\title{
TEN YEARS OF GROUP PRACTICE
}

\author{
ERIC WeBB, M.D., and H. B Graves, M.D. ${ }^{1}$
}

ThE DEVELOPMENTS in Anaesthesiology by Hollywood press agents in the past twenty years would be described as "Colossal, Stupendous, Gigantic." Advances in the basic sciences have been reflected in a greater understanding of anaesthesia and have introduced to our specialty such clinical applications as more adequate premedication, the tranquillizers, the relaxants, controlled respiration, one-lung respiration, replacement therapy, electrolyte control, hypotension, hypothermia, circulatory by-pass with oxygenators, and finally (maybe "finally" is the wrong word) elective cardiac arrest! But, in our opinion, a development just as important as these is the concept that an anaesthetic service to a given community can be rendered more proficiently by anaesthesiologists working as a group than by the same anaesthesiologists working as individuals. The exact terms of reference under which a group operates mayl differ widely, but, in our opinion, a full partnership offers the greatest advantages with the fewest disadvantages. We wish to discuss our own partnership with a view to elaborating this rather sweeping generalization.

At the Vancouver Gencral Hospital the principle of a closed anaesthetic staff, with patients assigned by the Chief of the Department, was established early in the twenties under Dr. D. D. Freeze's régime. This greatly facilitated organization of the Department in the immediate post-war period. In 1947, under Dr. M. Digby Leigh, the personnel of the Department was added to, the scope and load increased, and the teaching programme was greatly expanded. The hospital charged and collected the fees, and the anaesthetists were on a part-salary, part fee-forservice basis, paid by the Hospital. When the British Columbia Government announced its hospital insurance scheme, to commence in January, 1949, the anaesthesiologists at the Vancouver General |Hospital immediately informed the Administrator of the Hospital that as of September 15, 1948, they would bill patients privately, but in all other aspects continue to provide exactly the same service that had been provided previously. The eleven staff members formed the partnership known as "M. Digby Leigh \& Associates." When Dr. Leigh left the Group in 1953, the title was changed to "Associated Anaesthetic Services." Of the eleven charter members, four are still with the group, which has grown to include twenty-three members. Early in its history, one member left to help: inaugurate a Department of Anaesthesia at Royal Columbian Hospital, New Westminster. Two others left to inaugurate the Anaesthetic Department of the Grace and Burnaby Hospitals. In 1953, Dr, Leigh and Dr. Belton left for the Children's Hospital in Los Angeles. Two others retired. The replacements have been made from various training schools. Fourteen of our partners are graduates

1Associated, Anaesthetic Services, 829 West Broadway, Vancouver 9, B.C. 
of our own training programme; two were trained at the University of Toronto; two at McGill; and one received his training in Britain. In the ten years we have been in operation, we have had three men leave before becoming full partners to take up practice somewhere else. At present, the 23,000 cases per year for which we are responsible are looked -after by the twenty-three partners of Associated Anaesthetic Services, two part-time salaried employees (one on supervised practice), and a group of ten residents.

The contact of anaesthesiologists with a surgical patient is a four-party situation. In the centre, of course, is the patient, with the surgeon and anaesthetist standing close by. In every instance there is somewhere in the picture the administrator of the hospital. Each of these four stand to benefit greatly from the group practice of anaesthesia.

\section{The Patient}

The patient ordinarily has no private anaesthetist whom he wishes to look after him. Under a system which guarantees him the services of a qualified anaesthesiologist, he is safely and comfortably guided through his surgical adventure. If, as occurs occasionally, the patient has a personal preference for a particular member of the group, this is respected and arrangements are made accordingly. Physicians are allowed to request aihaesthetists for themselves and their families, but not for their patients. All emergency anaesthesia is performed by a qualified anaesthetist, with or without a resident present. If the patient's condition should warrant two staff anaesthetists, two are assigned.

\section{The Surgeon}

All partners are adequately trained in all aspects of anaesthesia and our surgeons are accustomed to having any member of our group in attendance. Some of us are more pleasant to work with than others, but all have the reputation of doing a good, safe, more than adequate anaesthesia. All elective anaesthesia is assigned by the anaesthetist-in-charge. All emergency anaesthesia is booked by the first anaesthetist on call, after consultation with the Operating Room Supervisor. The surgeon has no trouble in "arranging for" an anaesthetist, because when the case is booked, that has been looked after for him. In this day of "possible radicals," exploratory thoracotomies which turn into either marathons or closures, slow surgeons, and particularly in a hospital with as many operating rooms as ours has (eighteen), it is not infrequent for a single operating room to be either hours behind schedule or empty. When a partnership exists, switches in bperating room schedules are more easily arranged and no one is upset. Personal income is not involved, and everyone is happy. We try to ensure that any surgeon and anaestheist who wish to work on a particular problem with regard to patient care may do so. Then the decision reached and the information gained are shared at a staff meeting, and everyone benefits.

For good reasons, which nearly anyone can appreciate, we have created a team which does the open-heart pump-oxygenator cases. These men were subsidized to an extent during the time they were working out their laboratory 
efforts, and we feel this has provided better care of these very difficult cases. These cases are, however, the only cases which are "the property," as it were, of any special anaesthetist.

With the patient in the post-anaesthetic recovery room, the surgeon, of course, has his share of the after-care responsibility. But, with so many of us available, the recovery room patients are obviously going to get the early attention to emergencies that make this type of service so valuable. The recovery room nurses are, directly responsible to the anaesthetic staff.

\section{Administration}

With a group of qualified anaesthesiologists, the administrator of the Hospital can be assured that at all times he has a Department of Anaesthesia of which he can be proud. We are on call for emergency resuscitation needs at any time. Staff anaesthetists are present in the hospital twenty-four hours out of every day, seven days a week, fifty-two weeks a year.

\section{The Anaesthetist}

Let us quote verbatim the introduction to our partnership agreement:

Whereas the Parties hereto are agreed in their desire to practice Anaesthesiology in that manner in which is most likely to produce good medicine and good citizenship, and believe with deep sincerity that all practice of medicine should be governed by strict adherence to a code of ethics such as that expressed by the College of Physioians and Surgeons of British Columbia. Now this agreement witnesseth that the Parties hereto have agreed to enter into. Partnership for the practice of their profession, specializing as aforesaid, upon the terms and conditions and under and subject to the provisions hereinafter contained.

Further the Parties hereto. are agreed that it will be the constant dim of this Partnership to promote and raise the standards of Anaesthesia by diligent care of patients, by attaining knowledge in all ways, and by teaching, both ip undergraduate students and other qualified Physicians.

And further, the Parties hereto believe that by joining together in Partnership, all Members can and should share their time in proper proportion between the practice of Anaesthesiology, the study of their profession and specialty, and the care and enjoyment of their families. And also that they can help one another in daily work, ensure freedom from financial worries in time of sickness, and share with each other the costs and efforts of further training, attendance at conventions and meetings and all other things which will bring additional knowledge to the Partnership as a whole. And the Parties hereto believe that all others who, from time to time, may sign this Agreement must be willing to sacrifice aims of self and, in some measure, size of income, to share in and gain from the Association now created.

Working as we do, as a fully interdependant, mutually supporting partnership, we escape many of the galling features of an individual anaesthetic practice. Holidays are arranged well in advance, and do not interfere with our practice. If cases evaporate in the middle of the morning, it is not a catastrophe. Assigned to a morning of staff (charity) tonsils, our income does not suffer, and we are able to spend that morning as enthusiastically as if the cases were all private and remunerative.

When hypothermia started to become popular, we sent, at no personal expense, 
two of our group on a tour of several centres which were leading in this field. They returned to our hospital and have shared their experience with the Department. As mentioned previously, several of our men have been semi-subsidized in their efforts to put anaesthesia for open cardiac surgery on a well-founded basis. One of our members is the hospital pump-oxygenator expert, and this, while it has been somewhat costly, has contributed considerably to what we feel is one of the best series of open heart procedures done to date. In all humility, we have built on others' work, but we have also made our own contributions.

We have established a fairly extensive programme for covering our members if sickness overtakes them. During any twelve-month period, three ,months' sick leave is allowed. For each year with the partnership, a three-week / credit is established in the members sick leave accounts. A partner who has given good, healthy service for fifteen years, is thus allowed forty-five weeks of sick leave if he finally does become ill. During sick leave, all income is continued, except the overtime case allowance, for the first three months, and then a reduced income is available.

We hold a weekly staff meeting as one of our major edúcational features. At these meetings, theses are read, cases of interest discussed, the newer features of clinical and basic work reported. Journal club is rotated through the various staff members. This whole approach makes for a continuous postgraduate course for all of us. All in all, for anaesthetists, our partnership has a lot to offer on the positive side.

In order to arrange six weeks' vacation a year for each of twenty-three members, it is necessary to have three men on holidays most of the time. A roster from year to year decides in what order selection of holiday periods is to be made.

We have a large number of evening emergencies, and of course, our usual number of obstetrical deliveries in the night hours. These are covered by the two night anaesthetists, who come on daily at 8:00 P.M. and work until 8:00 A.M. These night anaesthetists have half a week on duty and then forty-eight hours free. They are not on duty in the day time. On call is a third anaesthetist who is assigned a light morning following, or left off the slate if circumstances permit.

A duty roster is maintained, and set up for six to eight weeks in advance. As the afternoon slated cases are finished, the anaesthetists on the lower calls are freed, and the higher call men carry on. The roster is flexible, so that switches in calls necessitated by special circumstances are easily arranged.

Probably the best feature of our operation is the fact that at all times, regardless of financial status, the patient is the direct responsibility of a staff member. We believe this is the proper manner to practise and teach anaesthesia. This does not mean that the residents stand by and watch. It does meanthat every patient, however, has a staff anaesthetist personally supervising the administration of his anaesthetic. The arguments may be raised that this makes cowards of our residents; that they do not develop the habit of making their own decisions; that they are not matured. This is not necessarily so, if the supervision is done carefully and if each decision is made on a consultative and educative basis, rather than a "just do as I say" basis. 
The financial return of each operation is pgoled. Each member ot the partner-1, ship receives a basic allowance per four-week period, a per hour allowance for work done between 1 P.M. and 8 A.M., and on Sundays and holidays, payable monthly, and the residue is divided as a quarterly dividend. Junior partners purchase their interest by a system of increasing participation in the residual monies. New entrants into the group are on probation for one year. During this time, professional capacity and personal compatability and the aequisition of "group mindedness" are carefully assessed. The professional ability is of no more importance than the compatibility, and might be of even less concern.

\section{Disadvantages}

The biggest single disadvantage to our type of practice is that, at all times, we must forget our own selfish ends, and work together as a really unified group. This is difficult for some people, and impossible for others. Self-advertising, selfishness, avoiding responsibility cannot be condoned, and the little things that make actual practice more pleasant, coffee relief, starting an intravenous, lending a helping hand, etc., come to the fore. Each individual has to be co-operative and "group" conscious.

One large area of the anaesthesiologists' field is the provision of service to the obstetrical patient. No one who has ever looked at this problem can come to any other decision than that we as anaesthesiologists, have a great deal to offer, and furthermore, a duty to make our services available in the case room. All is not that simple, however, and it is very easy to appreciate why many obstetrical departments are woefully neglected by their anaesthetists. Tradition, abetted by a lack of education by us of our obstetrical confrères, has kept fees for this work much lower than other anaesthetic fees. The hours are bad; the volume of work is unpredictable; and scheduling of a programme of obstetrical cases is impossible. Daytime cases interfere with surgical work, evening cases interfere with relaxation, and night cases interrupt sleep. Sometimes for hours not a single patient is being delivered, and without warning, three or four mothers are crowning at once! Recognizing our responsibility to the case room, we have come up with an answer to many of these undesirable problems. One staff man with a resident is assigned for a four-week period to the case room to cover the hours from 8 A.M. to 4 P.M. The staff man can initiate the resident to obstetrically oriented anaesthesia, with a certain continuity of approach. Ordinarily, the rest of the group can forget about the case room work for this period of the day, but if work load suddenly gets very heavy, hèlp can be quickly obtained from the general pool of anaesthetists in the other buildings. After 4:00 P.M., the case room calls are covered by the general call group. We have found that while this programme is somewhat expensive to the group, it covers the general obstetrical load with the least bother to us, and gives most effective service to the mother and obstetrician. We have adopted the general philosophy of "anaesthesia for delivery" rather than "prolonged regional anaesthesia for first stage" as our personal and combined attitude. While some may quarrel with this view, we have felt that, economically, prolonged regional anäesthesia presents too many problems, and we prefer to 
restrict this type of anaesthesia to cases where it is definitely indicated for medical reasons.

\section{Teaching}

Every anaesthetist on this continent, and especially in Canada, can think back to the days when the teaching of our specialty was in the hands of a very small group: Bourne, Griffith, Leigh, Aikenhead, Watts, Stewart, Shields, Robson, Leech, Freez-and no intentional slight is meant if we have omitted your mentor. We have followed in the steps of these men as closely as possible in attempting to spread knowledge of an enthusiasm for modern anaesthesia. Undergraduates spend a week in the Department, usually with one staff man for the whole week, and an attempt is made to show them the broad implications rather than make them proficient in one or two restricted techniques. Interns, on the other hand, are with us for a month, and because some of them are going to be in practices where they must administer some anaesthetics without further training, an attempt is made to give them a high degree' of safety and proficiency in several simple and widely applicable techniques, and at the same time provide some idea of the broader reaches of the field.

Many doctors practising in British Columbia are forced by physical factors to give their own anaesthetics, and in many areas the physician saturation is such that anaesthetics are given after scant or no training. We have many applications for short training periods from this group of the profession. We feel that while short training is not as desirable as longer periods of at least a year, there is nevertheless a place for three-month courses for those doctors forced to work in a moderately isolated area.

Since 1947, when the reorganization of the Department took.place, we have had sixty-four residents pass through the department: fifty of these have been certified by the Royal College of Physicians and Surgeons, and two have obtained their F.R.C.P.(C). Nine of the fifty certified have' qualifications. to sit for the F.R.C.P. (C) if they so desire. Twelve were from the United States or withdrew. At present, there are nineteen in the Post-Graduate Course in Vancouver.

Close contact is maintained with the university departments in the basic sciences, and for eight years we have had a fellowship in Basic Science at the University of British Columbia supported by three pharmaceutical firms. The lecture programme for students, interns, and postgraduate courses is divided up among the members of the group so that it does not fall on one or two sets of shoulders, and at the same time, the beneficial effect of preparing a series of lectures is spread around. As pointed out previously, our residents are not used to stock certain departments to relieve the need of staff men, but are in constant contact with one of the staff, who is in charge of the cases that the resident may do.

We may have created an impression that Associated Anaesthetic Services not only "knows all the answers," but in addition has a "corner on the answers." This, we regret to say, is not true. In ten years of existence, we have gone up many blind alleys. We have been lost at times in a maze which, to our surprise. led us 
out to a position we had occupied several years previously. Mapy of our habits, which for years have appeared satisfactory, suddenly develop large cracks. As an example, our sickness policy seemed excellent, but recently a nearly catastrophic spell hit us when three of us were off with long illnesses. This brought home to us that our arrangements needed exploring-and we hope to arrivel at a better answer.

The ratio of staff to case load, the possibility of increasing work load, by reason of adding work or the new opening of operating rooms, etc., the most efficient use of present staff are problems which are always present. Retirement policy has to be worked out although most of our group are not really seriously considering retirement in the next year or so.

The political aspects of the group are for the most part handled by an elected executive of four, plus the director of the hospital department ex officio. The executive are elected annually, and select from their own number a chairman, secretary, office supervisor, and financial chairman. Meetings of the executive are called as often as necessary, and a general group meeting is held about once a month, but at least every seventy days.

Members of our group are encouraged to take part in the broader aspects of both medical and non-medical community affairs. One of our group acts as director of the hospital department, is on the hospital medical board, is Clinical Associate Professor at the University, and acts on the British Columbia executive of the Canadian Medical Protective Association. Another has acted for the past several years on the Canadian Medical Association, B.C. Division, Executive, a third is on the Board of Directors of S.A.M.S. The B.C. Division of the Canadian Anaesthetists' Society executive has two or three representatives at all times. Participation in community affairs is encouraged.

The history and experience of a large group of anaesthetists over the past decade may be of interest, and we trust of use to the specialty of anaesthesia, which, perhaps more than any other branch of medicine, tends to be most effectively practised in partnership.

All aspects of the anaesthesiologist's relationship to his patients, surgical colleagues, hospital administrator, the community in general and fellow specialists benefit from this type of association. 